서울 및 경기지역 식육판매업소의 위생관리 실태분석 - HACCP 지정업소와 미지정업소 비교를 중심으로 -

\author{
이주연 · 백진경 ${ }^{1} \cdot$ 황혜선 ${ }^{1} \cdot$ 이주은 ${ }^{2} \cdot$ 신원선 $^{3} \cdot$ 김현욱 $\cdot$ 백현동 ${ }^{4} \cdot$ 홍완수 $^{1 *}$
}

축산물위해요소중점관리기준원, ${ }^{1}$ 상명대학교 외식영양학과, ${ }^{2}$ 연세대학교 식품영양과학연구소 ${ }^{3}$ 한양대학교 식품영양학과, ${ }^{4}$ 건국대학교 동물생명과학부

\title{
Survey of Hygienic Condition and Management of Meat Markets in Seoul and Gyeong-Gi Area, Korea - HACCP-certified and Non Certified -
}

\author{
Joo-Yeon Lee, Jin Kyoung Paik ${ }^{1}$, Hye Sun Hwang ${ }^{1}$, Joo Eun Lee ${ }^{2}$, Weon Sun Shin ${ }^{3}$, \\ Hyoun Wook Kim, Hyun-Dong Paik ${ }^{4}$, and Wan Soo Hong ${ }^{1 *}$ \\ Korea Livestock Products HACCP Accreditation Service, Anyang 430-821, Korea \\ ${ }^{1}$ Department of Foodservice Management and Nutrition, Sangmyung University, Seoul 110-743, Korea \\ ${ }^{2}$ Research Institute of Food and Nutritional Sciences, Yonsei University, Seoul 120-746, Korea \\ ${ }^{3}$ Department of Food and Nutrition, Hanyang Universtiy, Seoul 133-791, Korea \\ ${ }^{4}$ Division of Animal Life Science, Konkuk University, Seoul 143-701, Korea
}

\begin{abstract}
Considering the increasing trends of the consumption of livestock products in Korea, proper hygienic management and policies for ensuring their safety to protect public health and strengthen consumer confidence are demanded. It is particularly important to manage the livestock distribution processes to provide safe meat and meat products. This study was conducted to examine factors related to the hygiene management of livestock products and to check out the condition of hygienic management in meat markets. To accomplish this, 156 meat markets divided into HACCP-certified and non certified and evaluated for five factors, which received the following scores: facility and equipment management (1.00/2.0 points, 50.0\%), storage and transport management (1.93/2.0 points, $96.5 \%)$, work place management $(0.76 / 2.0$ points, $38.0 \%)$, personal hygiene management $(0.75 / 2.0$ points, $37.5 \%)$, and inspection management $(0.22 / 2.0$ points, $11.0 \%)$. The results revealed that the scores of HACCP-certified meat markets were significantly higher than those of the non certified markets $(p<0.05, p<0.01, p<0.001)$. These findings suggest that meat markets that are not HACCP-certified must improve hygienic management conditions and educate their employees to improve the safety of livestock products during distribution.
\end{abstract}

Key words: livestock product, meat market, hygienic management, HACCP

서 론

축산물은 농산물 중에서도 부패가 용이하여 안전관리가 매우 중요하며, 최근 국내·외에서 발생한 구제역, 조류 인플루엔자, 신종플루 등의 가축유래 질병으로 인하여 축 산물 안전성에 대한 소비자들의 경각심이 더욱 고조되었

*Corresponding author : Wan Soo Hong, Dept. of Foodservice Management and Nutrition, Sangmyung University, Seoul 110743, Korea. Tel: 82-2-2287-5350, Fax: 82-2-2287-0071, Email: wshong@smu.ac.kr
다(Lee, 2007).

우리나라는 국민소득 수준의 향상과 식품산업의 발전으 로 식품소비 패턴이 변화되어, 쌀의 소비가 줄어들고 상 대적으로 축산물, 유제품, 과일류 등과 각종 가공식품의 소비가 증가하고 있는 양상을 보이고 있다(Jeon et al., 2005). 농림수산식품부 통계에 의하면 우리나라 1 인당 육 류 소비량은 1997년 쇠고기 $7.9 \mathrm{~kg}$, 돼지고기 $15.3 \mathrm{~kg}$, 닭 고기 $6.1 \mathrm{~kg}$ 로 총 $29 \mathrm{~kg}$ 에서 2007 년도에는 쇠고기 $7.6 \mathrm{~kg}$, 돼지고기 $19.2 \mathrm{~kg}$, 닭고기 $8.6 \mathrm{~kg}$, 총 $35 \mathrm{~kg}$ 으로 매년 증가 추세에 있다(MIFAFF, 2009). 
세계보건기구(WHO)에 의하면 식품유래 질병의 실제 발 생 건수는 보고된 건수의 300 350배이며, 선진국은 발생 건수의 $10 \%$, 개도국은 발생 건수의 $1 \%$ 이하만이 보고되 고 있고 국내의 식품유래 질병 발생 건수와 환자수는 매 년 증가하고 있다(KFDA, 2009). 지난 1999년부터 2002년 까지 축산물 수거검사를 실시한 결과 부적합 비율은 1999 년 $1.1 \%$ 에서 2000 년에는 $0.7 \%$ 로, 2001 년의 $0.5 \%$ 가 2002 년에는 $0.25 \%$ 로 감소하였지만 2001년부터 2002년까지 위 생 감시 실적을 보면 업소의 위반 비율이 도축업에선 $3.6 \%$ 에서 $4.4 \%$ 로, 가공업에선 $4.7 \%$ 에서 $12 \%$ 로 증가하였다. 이 와 같이 1997년부터 현재까지 위해요소중점관리제도 (HACCP)가 적용 - 확대되고 있지만 소비자의 건강과 생 명에 위해를 가할 수 있는 위험률은 점점 높아지고 있다 (Lee, 2005).

이러한 배경 하에 식품 안전성을 보증할 수 있는 최선 의 위생관리 기법으로 인정받고 있는 위해요소중점관리제 도(HACCP)가 식육위생관리상 중요한 도축장에는 2003년 7월 1 일부터 의무 적용되었다. 그러나 도축장 이외의 다 른 업종의 $\mathrm{HACCP}$ 적용은 업체의 선택에 따라 자율적으 로 적용하도록 되어있다. 2010년 3월 15일 현재 우리나라 의 축산물 작업장 중 $\mathrm{HACCP}$ 지정업체수는 총 2,623개이 며, 이 중 가축사육업 및 종축업이 1,211 개, 배합사료공장 이 82 개, 그 외 축산물 작업장이 1,330 개소에 이르고 있다. 또한 축산물 작업장 중에서는 가공업체가 303개, 식육포 장처리업체가 739 개, 식육판매업소가 213 개, 보관 및 운 반 업체가 각각 2와 12 개소이다(KOLPHAS, 2010; Lee, 2009). 이와 같이 우리나라의 축산물에 작업장에 대한 $\mathrm{HACCP}$ 적용은 매우 큰 비중을 차지하고 있으며 축산물 의 위생관리나 안전성 확보를 위해 중요한 역할을 하고 있다.

오늘날 인터넷의 급속한 성장으로 온라인 전자상거래시 원산지 표시제도가 도입되어 실행되고 있으나 철저한 감 독과 지도가 부족하여 오히려 수입 원산지가 국내산으로 판매되는 등의 문제점을 유발하고 있다. 또한 육안으로 상 품을 직접 확인할 수 없기 때문에 축산물의 위생 상태나 안전성을 파악하기 어려워 보다 확실하고 투명한 방법으 로 축산물의 안전성과 위생 상태를 확인하는 다양한 제도 들이 마련되어야 할 것이다(Nam et al., 2007b).

농림수산식품부는 환경 변화에 따라 사육-생산-유통 등 의 위해 축산물 발생 가능성이 증대되고 국내·외적인 여 건 변화에 따른 위생관리 강화 필요성의 증대로 축산물의 위생 감시를 더욱 강화하기로 하였는데, 이는 축산물의 대 량생산 - 대량유통 및 집단 급식소에서의 병원성 미생물 및 유해물질 잔류로 인한 식중독과 식품유래 인체 유해물 질의 오염 기회가 증가하고 가축 사육의 대규모화나 집단 화로 인하여 동물약품 사용량이 늘어나고 있기 때문이라 고 하였다(FSIS, 2009). 특히 국민소득 수준 향상으로 인 수공통전염병, 병원성 미생물, 항생물질 - 합성항균제 - 농
약 · 호르몬제 등 유해물질이 없는 안전한 축산식품을 선 호하고 축산물에 대한 안전성 확보에 대한 요구가 증가하 고 있으며, WTO의 SPS(Sanitary and Phyto-sanitary, 동식 물검역협정)협정에 따라 각국은 식품위생안전관리를 위해 국제기준과 규격을 우선 적용하도록 함에 따라 농축산물 및 식품의 교역에 $\mathrm{WHO} / \mathrm{FAO}$ 의 Codex Alimentarius(국제 식품규격위원회)에서는 $\mathrm{HACCP}$ 을 채택하여 적용하도록 권 고하고 있다. 이에, 여러 선진국들은 식품의 생산, 가공, 유통 등 전 과정 및 관련 업체들의 위생안전관리체계를 $\mathrm{HACCP}$ 에 근거하여 운영하도록 권고 혹은 의무적용하고 있는 실정이다. 최근 우리나라에서도 자유무역이 활발해 지면서, 각 업체에서는 축산식품의 수출을 증대하고 국제 경쟁력을 확보하기 위해 $\mathrm{HACCP}$ 적용을 활발히 하고 있 으며, 국가에서는 최종 소비자의 건강을 보호하고 신뢰를 구축하기 위해 유통단계를 포함한 전 단계에 대한 위생관 리 강화가 이루어지도록 하기 위해 축산물 관련업체의 위 생감시를 한층 강화하고 있다(FSIS, 2009).

따라서 본 연구에서는 축산물의 유통단계 중 최종 소비 자와의 접점이 되는 식육판매업소를 대상으로 효율적인 위생관리를 수행하기 위한 필요 위생관리 항목을 규명하 기 위해, 서울 및 경기지역 식육판매업소들 중 $\mathrm{HACCP}$ 을 적용 혹은 미적용하는 업체들에 대한 위생관리 실태를 조 사- 분석하였다.

\section{조사대상 및 방법}

\section{조사대상}

본 연구는 서울 및 경기지역 식육판매업소를 대상으로 하였다. 조사대상은 서울과 경기지역의 협조가 가능한 $\mathrm{HACCP}$ 지정업소와 $\mathrm{HACCP}$ 미지정업소로 구분하여 선정 하였으며, $\mathrm{HACCP}$ 지정업소 15 곳과 미지정업소 141 곳이 조사되었다. 본 조사는 예비조사를 포함하여 2008년 12월 부터 2009년 8월까지 전문 연구원이 현장조사를 실시한 후 위생실태 조사지를 작성하였다.

\section{조사내용 및 방법}

본 연구는 타당한 평가와 평가의 공정성을 위하여 체크 리스트와 체트리스트의 기준서를 개발하였다. 위생실태 평 가를 위한 체크리스트는 농림수산식품부 축산물 $\mathrm{HACCP}$ 선행요건(NVRQS, 2006), 식품의약품안전청고시 HACCP 선행요건(KFDA, 2008), 평가도구에 관련된 선행연구(Jeon, 2005; Lee, 2006), 농림수산식품부 축산물 위생감시지침 (NVRQS, 2009), Food Safety and Inspection Service (USDA, 1990) 등을 기초로 하여 개발하였고, 국내 축산 물HACCP 선행요건은 위생관리를 위한 상세기준이 제시 되어 있지 않기 때문에, 본 연구에 타당한 평가 도구로 체 크리스트의 기준서를 개발하였다. 체크리스트는 업소 일 
반사항과 위생관리로 구분하여 작업장관리 영역(21항목), 제조시설관리 영역(5항목), 보관 및 운반관리 영역(9항목), 개인위생관리 영역(5항목), 검사관리 영역(3항목)으로 총 5 개영역의 43 항목으로 구성하였고, 체크리스트의 기준서 는 양호(2점), 보통(1점), 미흡(0점)으로 분류하여 평가의 공정성을 두었으며, 해당하는 곳에 표시할 수 있도록 체 크리스트를 구성하였다. 작성된 체크리스트는 협조 가능 한 식육판매업소를 중심으로 현장 방문하고 관련분야 전 문가의 자문을 받아 수정 - 보완하였다.

식육판매업소의 위생관리 실태조사를 위하여 급식위생 을 전공하는 대학원생들로 조사팀을 구성하였으며, 예비 조사를 위한 현장방문 시 축산위생 전문가가 중점적으로 조언한 위생관리 부분과 조사방법에 대하여 사전교육을 실시하였다. 2 인 1 조로 팀을 이루어서 식육판매업소를 직 접 현장 방문하여 식육판매업소 일반사항과 현황에 대해 업계 담당자와의 인터뷰와 관찰을 통하여 현장조사를 실 시하였다.

\section{통계분석}

수집된 자료는 SPSS(Statistical Package for Social Science) Win 15.0 을 이용하여 통계처리하였고, 조사대상 업소의 일 반사항과 위생실태 조사결과 점수는 빈도와 백분율, 평균 과 표준편차의 기술 통계량을 이용하여 분석하였으며, $\mathrm{HACCP}$ 지정업소와 $\mathrm{HACCP}$ 미지정업소 간의 전체 평균점 수와 영역별 비교는 t-test를 사용하였다.

\section{결과 및 고찰}

\section{조사대상 식육판매업소의 일반사항}

조사대상 156 곳 식육판매업소의 일반사항은 Table 1 과 Table 2에 나타내었다. 2008년 9월말을 기준으로 전국 44,012 곳의 식육판매업소 중 HACCP지정을 받은 업소는 전국 213곳(2010.3.15 현재)이다. 본 연구에서는 대상업소

Table 1. General characteristics of respondents (I)

\begin{tabular}{clc}
\hline \hline & Variables & Mean \pm SD \\
\hline & Total area $\left(\mathrm{m}^{2}\right)$ & $71.05 \pm 117.31$ \\
& Refrigerator $\left(\mathrm{m}^{2}\right)$ & $16.76 \pm 34.28$ \\
Area & Freezer $\left(\mathrm{m}^{2}\right)$ & $15.19 \pm 31.62$ \\
& Workplace $\left(\mathrm{m}^{2}\right)$ & $25.51 \pm 39.83$ \\
& Inspection room $\left(\mathrm{m}^{2}\right)$ & $0.28 \pm 1.55$ \\
\hline Total & Regular worker (No.) & $1.76 \pm 2.37$ \\
employees & Non-regular worker (No.) & $1.31 \pm 2.86$ \\
\hline Business & Vendor (No.) & $2.94 \pm 2.53$ \\
enterprise & Vendee (No.) & $1.56 \pm 6.98$ \\
\hline Total sale price (1,000 Won) & $580,250 \pm 1,180,418$ \\
Operational period (year) & $18.00 \pm 13.45$ \\
HACCP-operated period (month) & $8.86 \pm 8.39$ \\
\hline
\end{tabular}

Table 2. General characteristics of respondents (II)

\begin{tabular}{|c|c|c|c|}
\hline & Variables & $\begin{array}{l}\text { Frequency } \\
\text { (n) }\end{array}$ & $\begin{array}{c}\text { Percentage } \\
(\%)\end{array}$ \\
\hline \multirow{5}{*}{$\begin{array}{l}\text { Shape of } \\
\text { vendors }^{1)}\end{array}$} & Butchery & 51 & 26.4 \\
\hline & Guild of livestock industry & 20 & 10.4 \\
\hline & Wholesaler & 117 & 60.6 \\
\hline & Retailer & 1 & 0.5 \\
\hline & Others & 4 & 2.1 \\
\hline \multirow{5}{*}{$\begin{array}{l}\text { Shape of } \\
\text { vendees }^{1)}\end{array}$} & General customer & 147 & 75.4 \\
\hline & Restaurant & 17 & 8.7 \\
\hline & Wholesaler & 16 & 8.2 \\
\hline & Retailer & 12 & 6.2 \\
\hline & Institutional foodservice & 3 & 1.5 \\
\hline \multicolumn{2}{|c|}{ Location of Seoul } & 133 & 85.3 \\
\hline market & Gyeonggi-do & 23 & 14.7 \\
\hline \multirow{2}{*}{$\begin{array}{c}\text { Shape of } \\
\text { ownership }\end{array}$} & Own & 16 & 10.3 \\
\hline & Rent & 140 & 89.7 \\
\hline
\end{tabular}

${ }^{1)}$ Shape of vendors and vendees are multiple responses.

의 접근성과 협조 용이성을 위하여 서울 - 경기지역 소재 업소로 한정하여 조사를 실시하였다. 본 연구에서는 식육 판매업종에서 서울과 경기도 지역의 $\mathrm{HACCP}$ 지정업소 15 곳, 미지정업소 141 곳을 대상으로 총 156 곳을 조사하였다.

작업장 면적은 평균 $71.05 \mathrm{~m}^{2}$ 이었고 전체 직원은 평균 1.76 명의 정규직원과 평균 1.31 명의 비정규직 직원을 고 용하고 있었다. 거래업체는 평균 1.56 개의 공급업체와 평 균 2.94개의 납품업소로 나타났다. 공급업체로는 도매업 체가 평균 $60.6 \%$ 로 가장 높은 비율을 나타냈으며 다음으 로 도축장이 평균 $26.4 \%$ 로 조사되어, 대다수의 조사업소 들이 도매업체에서 1 차 가공된 식육을 받는 것을 알 수 있었다. 납품업체로는 일반소비자가 평균 $75.4 \%$ 로 가장 높은 비율을 차지하였고, 다음으로 일반식품접객업소가 평균 $8.7 \%$ 이었다. 지역적 분포는 서울지역 133 곳 $(85.3 \%)$, 경기지역 23 곳 $(13.7 \%)$ 이었으며 건물 소유형태로는 자가 건물 16 곳 $(10.3 \%)$, 임대 140 곳 $(89.7 \%)$ 이었다. 취급품목에 서는 쇠고기와 돼지고기가 $40 \%$ 와 $60 \%$ 의 비율로 분포하 였다.

\section{위생관리 영역별 평가 결과}

식육판매업의 위생관리를 영역별로 구분하여 평가한 결 과, $\mathrm{HACCP}$ 지정업소와 $\mathrm{HACCP}$ 미지정업소의 전체 평균은 0.73점/2.0점(36.5\%)이었으며, HACCP 지정업소는 1.68점/2.0 점(84.0\%)인 반면 HACCP 미지정업소는 0.63점/2.0점(31.5\%) 이었다. 전체 평균의 5 개 영역 중 가장 높은 점수를 획득한 영역은 제조시설관리(1.00점/2.0점, 50.0\%)였고, 다음이 보관 및 운반관리(0.93점/2.0점, $46.5 \%)$, 작업장관리(0.76점/2.0점, $38.0 \%)$, 개인위생관리 $(0.75$ 점 $/ 2.0$ 점, $37.5 \%)$, 검사관리 $(0.22$ 점 12.0 점, $11 \%$ )의 순으로 나타나, 검사관리 영역의 점수가 가 장 낮게 조사되었다. $\mathrm{HACCP}$ 지정업소의 경우 5 개 영역의 
평균 중 가장 높은 점수를 획득한 영역은 검사관리(1.8점/ 2.0점, 90.0\%)였고, 다음으로 제조시설관리(1.73점/2.0점, $86.5 \%)$, 보관 및 운반관리(1.69점/2.0점, $84.5 \%)$, 작업장관리 (1.66점/2.0점, $83 \%$ ), 개인위생관리(1.51점/2.0점, $75.5 \%)$ 의 순 으로 조사되어 가장 낮은 영역은 개인위생관리 영역이었다.

$\mathrm{HACCP}$ 미지정업소의 경우 5 개 영역 평균 중 가장 높 은 점수를 획득한 영역은 제조시설관리(0.92점/2.0점, $46.0 \%)$ 이었고, 다음이 보관 및 운반관리(0.86점/2.0점, $43.0 \%)$, 개 인위생관리( 0.67 점/2.0점, $33.5 \%)$, 작업장관리(0.66점/2.0점, $33.0 \%)$, 검사관리 $(0.05$ 점 $/ 2.0$ 점, $2.5 \%)$ 의 순으로, 가장 낮은 영역은 검사관리 영역이었다(Fig. 1). 이는 HACCP 미지 정업소의 경우 미생물 검사시설이 없거나, 위탁검사도 이 루어지지 않아 낮은 점수를 받게 되었다. $\mathrm{HACCP}$ 지정업 소의 경우 개인위생관리영역 점수(1.51점)가 HACCP 미지 정업소의 점수( 0.67 점)보다는 높았으나, 다른 항목들에 비 해 가장 낮은 점수를 받았다는 점에서 종사자의 기본적 위생 관념과 실천을 위해 지속적인 교육과 지도가 필요한 것으로 여겨진다. 우리나라 4대권역의 쇠고기 판매업소 707 개를 대상으로 위생 모니터링을 한 Nam 등(2007a)과 서울시내 300 개 축산물 판매업소를 대상으로 위생실태를 조사한 Park 등(2007)의 조사결과에 의하면 조사대상 업 소의 위생실태 중 위생복, 위생모, 위생화 착용 여부의 적
합률이 낮게 조사되었다고 한다. 따라서, 본 연구의 조사 대상인 $\mathrm{HACCP}$ 지정 및 미지정 업소에서는 위생복의 착 용 및 일반적인 개인위생관리에 더욱 철저할 수 있도록 관리하여야 할 것이며, 본 항목의 관리소홀 시 축산물 안 전에 대한 위협과 소비자 건강에 미치는 부정적 영향이 클 수 있으므로, 특히 HACCP미지정업소는 위생개념에 대 한 인식과 태도의 개선을 위한 관리와 대처 마련이 절실 히 요구된다(Lyu, 2004; Nel et al., 2004).

\section{작업장관리}

Table 3은 작업장관리에 대한 업소 평가 점수를 제시하 였다. 영역의 평균은 0.76점/2.0점(38.0\%)으로 평가되었고, $\mathrm{HACCP}$ 지정업소의 평균이 1.66 점 $(83.0 \%)$ 으로 미지정업 소 0.66 점(33.0\%)에 비해 높은 점수를 보였으며 유의적인 차이를 나타내었다 $(p<0.001)$.

3 개로 구분된 세부영역별 평가점수는 주변 환경과 건 물' 1.13점/2.0점(56.5\%), ‘작업장 시설 · 설비' 0.69점/2.0 점(34.5\%), ‘작업장 환경' 0.77점/2.0점(38.5\%)으로 나타나 '작업장 시설 - 설비'에서 가장 낮은 점수를 얻었다. 세부 영역별 평균 점수에서 '작업장 시설·설비'는 HACCP 지 정업소의 평균이 1.59 점/2.0점(79.5\%)으로 미지정업소 0.59 점/2.0점(29.5\%)에 비해 높은 점수를 보였으며 유의적 차

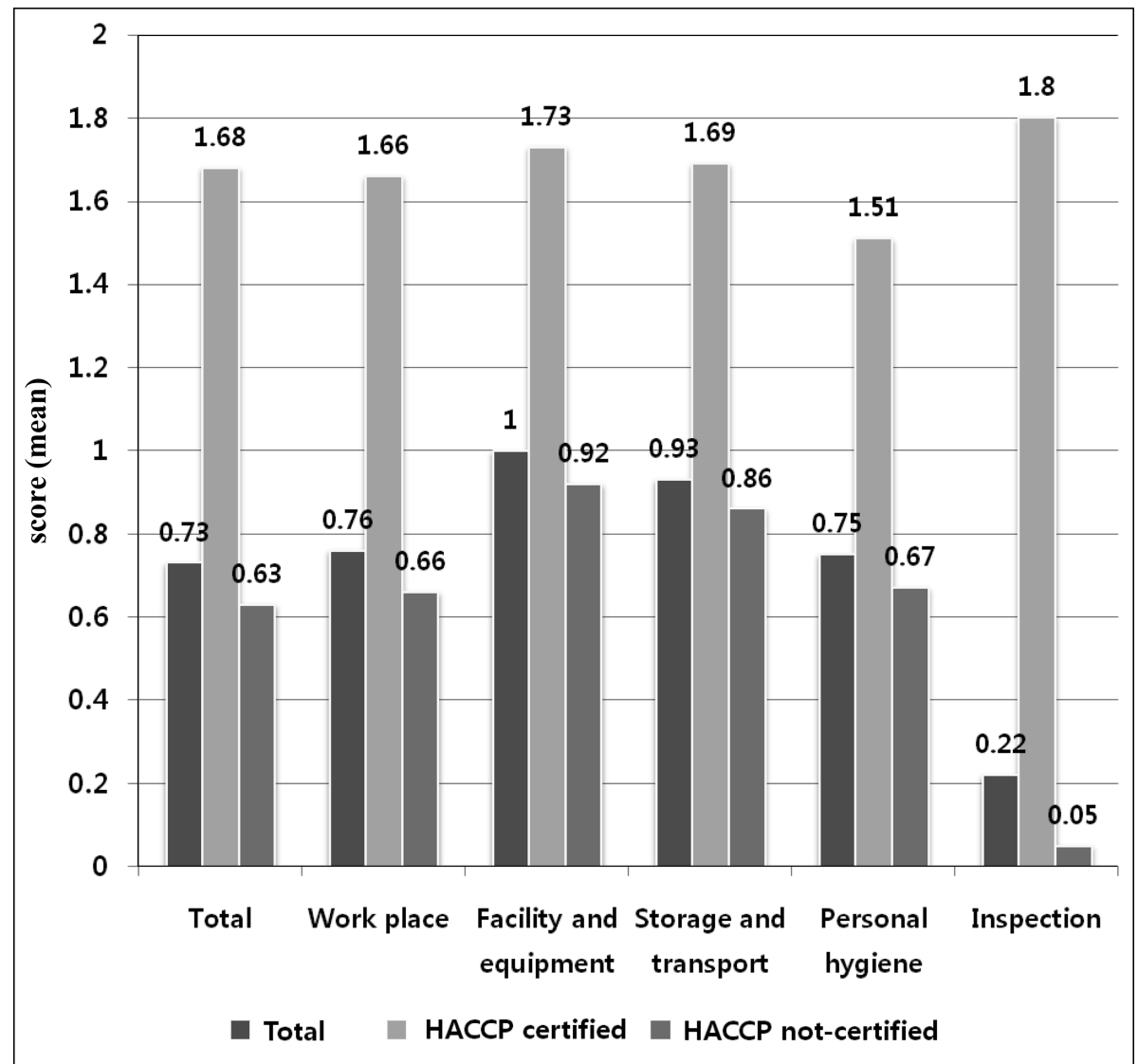

Fig. 1. Average scores of actual conditions associated with hygienic management in meat markets. 
이를 나타내었다 $(p<0.001)$. '작업장 환경'의 세부영역은 $\mathrm{HACCP}$ 지정업소의 평균이 1.70 점(85.0\%)으로 미지정업 소 0.67 점(33.5\%)에 비해 높은 점수를 보였으며 유의적 차 이를 나타내었다 $(p<0.001)$.

작업장관리 영역에서 가장 높게 평가된 항목은 '건물은 축산폐수, 화학물질, 기타 오염물질 발생시설로부터 축산 물가공품에 나쁜 영향을 주지 않도록 일정한 거리의 유지, 로 2.0 점 만점에 1.26 점 $(63.0 \%)$ 이었고, '화장실의 환기시
설 설치 및 방충망 설치여부'의 항목이 가장 낮은 평가를 받아 2점 만점에 0.31점(15.5\%)이었다.

지정업소는 '작업장은 독립된 건물이거나 다른 용도로 사용되는 시설과 분리(벽 · 층 등) 되어 있으며, 위생적인 상태로 유지'의 항목에서 2.0점/2.0점(100\%)으로 가장 양 호함을 보였고, 미지정업소는 건물의 위치에 대한 항목이 가장 높은 점수(1.19점, $59.5 \%$ )를 보였다.

지정업소에서 가장 낮은 평가를 받은 항목은 '화장실의

Table 3. Comparison of work place management domain in HACCP certified and non-certified meat markets

\begin{tabular}{|c|c|c|c|c|c|c|}
\hline & \multirow[b]{2}{*}{ Item } & & \multirow[b]{2}{*}{ Mean $\pm \mathrm{SD}$} & \multicolumn{2}{|c|}{ Mean \pm SD } & \multirow[b]{2}{*}{ t-Value } \\
\hline & & & & $\begin{array}{l}\text { HACCP } \\
\text { certified }\end{array}$ & $\begin{array}{c}\text { HACCP } \\
\text { not-certified }\end{array}$ & \\
\hline \multirow{8}{*}{$\begin{array}{l}\text { Environment } \\
\& \text { building }\end{array}$} & Location & Separation from contamination sources & $1.26 \pm 0.66^{1)}$ & $1.93 \pm 0.26$ & $1.19 \pm 0.65$ & $8.58^{* * *}$ \\
\hline & Building & Separation and sanitation of building or facility for food only & $0.99 \pm 0.75$ & $2.00 \pm 0.00$ & $0.89 \pm 0.71$ & $18.67^{* * *}$ \\
\hline & & Subtotal & $1.13 \pm 0.19$ & $1.97 \pm 0.05$ & $1.04 \pm 0.21$ & $15.21 * * *$ \\
\hline & & $\begin{array}{l}\text { Toilets for employees only and entrance of toilet far from } \\
\text { kitchen }\end{array}$ & $0.34 \pm 0.67$ & $1.07 \pm 0.96$ & $0.26 \pm 0.58$ & $3.18^{* *}$ \\
\hline & Rest room & Establishment of ventilator and insect net in bathroom & $0.31 \pm 0.65$ & $0.80 \pm 0.86$ & $0.26 \pm 0.61$ & $2.36^{*}$ \\
\hline & & $\begin{array}{l}\text { Establishment of hand wash stand in bathroom with warm } \\
\text { water, liquid soap and paper towels }\end{array}$ & $0.35 \pm 0.63$ & $1.00 \pm 0.23$ & $0.28 \pm 0.55$ & $2.94 *$ \\
\hline & Locker room & Locker room for employees only & $0.41 \pm 0.64$ & $1.33 \pm 0.62$ & $0.31 \pm 0.56$ & $6.63 * * *$ \\
\hline & Door & Waterproof and rigid material & $0.84 \pm 0.72$ & $1.93 \pm 0.26$ & $0.72 \pm 0.66$ & $13.98^{* * *}$ \\
\hline \multirow{8}{*}{$\begin{array}{l}\text { Workplace } \\
\text { Facility }\end{array}$} & Wall & $\begin{array}{l}\text { Waterproof material cleaned to prevent microbial contami- } \\
\text { nation }\end{array}$ & $0.97 \pm 0.74$ & $1.93 \pm 0.26$ & $0.87 \pm 0.70$ & $11.96^{* * *}$ \\
\hline & Floor & Waterproof material such as concrete that is well maintained & $1.13 \pm 0.70$ & $1.60 \pm 0.51$ & $1.08 \pm 0.70$ & $2.82 * *$ \\
\hline & Ceiling & $\begin{array}{l}\text { Easily cleanable material and structure and prevention } \\
\text { against condensation and microorganisms }\end{array}$ & $0.92 \pm 0.76$ & $1.93 \pm 0.26$ & $0.82 \pm 0.71$ & $12.46^{* * *}$ \\
\hline & Lighting & Proper level for work and protection with shields & $0.53 \pm 0.76$ & $1.93 \pm 0.26$ & $0.38 \pm 0.63$ & $18.21 * * *$ \\
\hline & Drainage & Structure for proper drainage and prevention of reverse flow & $0.99 \pm 0.71$ & $1.87 \pm 0.35$ & $0.89 \pm 0.68$ & $9.01 * * *$ \\
\hline & Window & $\begin{array}{l}\text { Waterproof, corrosion resistant material and protective film } \\
\text { to contain breaks }\end{array}$ & $0.80 \pm 0.75$ & $1.87 \pm 0.35$ & $0.69 \pm 0.69$ & $10.94 * * *$ \\
\hline & & Establishment of insect net & $0.69 \pm 0.89$ & $1.87 \pm 0.52$ & $0.56 \pm 0.83$ & $8.68^{* * *}$ \\
\hline & & Subtotal & $0.69 \pm 0.29$ & $1.59 \pm 0.43$ & $0.59 \pm 0.29$ & $8.85^{* * *}$ \\
\hline \multirow{9}{*}{$\begin{array}{l}\text { Workplace } \\
\text { Environment }\end{array}$} & Compartment & Compartment of clean and not clean zone in working area & $0.87 \pm 0.69$ & $1.93 \pm 0.26$ & $0.76 \pm 0.92$ & $13.87^{* * *}$ \\
\hline & Ventilation & Establishment of ventilation system in working area & $1.12 \pm 0.80$ & $1.87 \pm 0.35$ & $1.04 \pm 0.80$ & $7.36^{* * *}$ \\
\hline & \multirow{2}{*}{ Pest control } & $\begin{array}{l}\text { Establishment of air curtain, insect nets or doors for pre- } \\
\text { vention of insects and rodents }\end{array}$ & $0.40 \pm 0.69$ & $1.60 \pm 0.63$ & $0.28 \pm 0.56$ & $8.57^{* * *}$ \\
\hline & & $\begin{array}{l}\text { Regular interval sterilization for extermination of insects } \\
\text { and rodents }\end{array}$ & $0.75 \pm 0.59$ & $1.47 \pm 0.52$ & $0.67 \pm 0.54$ & $5.42 * * *$ \\
\hline & $\begin{array}{l}\text { Waste manag- } \\
\text { ement }\end{array}$ & Trash can and its cleanliness & $0.87 \pm 0.79$ & $1.93 \pm 0.26$ & $0.75 \pm 0.74$ & $12.96^{* * *}$ \\
\hline & \multirow{2}{*}{ Cleaning } & Cleaning equipment and cleaning outfits & $0.97 \pm 0.74$ & $1.87 \pm 0.35$ & $0.88 \pm 0.71$ & $9.07 * * *$ \\
\hline & & Proper schedule for cleaning & $0.41 \pm 0.63$ & $1.20 \pm 0.86$ & $0.33 \pm 0.54$ & $3.85^{* *}$ \\
\hline & & Subtotal & $0.77 \pm 0.27$ & $1.70 \pm 0.28$ & $0.67 \pm 0.28$ & $10.35^{* * *}$ \\
\hline & & Total & $0.76 \pm 0.30$ & $1.66 \pm 0.37$ & $0.66 \pm 0.30$ & $17.62 * * *$ \\
\hline
\end{tabular}

\footnotetext{
${ }^{1)}$ Score: 2 (excellent), 1 (normal), or 0 (poor) out of 2 points.
}

${ }^{*} p<0.05,{ }^{* *} p<0.01,{ }^{* * *} p<0.001$. 
환기시설 설치 및 방충망 설치여부로 0.80 점(40.0\%)이었 으며, 미지정업소에서 가장 점수가 낮은 항목은 종사자들 만의 전용 화장실의 설치 여부와 출입문이 작업장에 바로 면하지 않는 구조'와 ‘화장실의 환기시설 설치 및 방충망 설치 여부(0.26점, $13.0 \%)$ '로 화장실 시설에 대한 내용이 었는데, 많은 식품관리 시설에 대해서는 법적으로 그 내 용을 규정하고 있지만 실제 운영면에서는 설치내용과 위 생관리가 소홀한 경우가 많다(Kim, 2000). Hong과 Cho (2008)의 연구에 따르면 국립수의과학검역원의 HACCP 선 행요건과 비교하여 식품의약품안전청의 선행요건에서 추 가로 언급되는 내용 중 화장실 관리는 매우 중요하며 오 염 발생의 장소이므로 작업실과 구분하는 등의 세부적 관 리가 필요하다고 지적하였다.

작업장관리 영역의 모든 항목에서 지정업소와 미지정업 소의 평가 점수가 유의한 차이를 보였으며 $(p<0.05, p<0.01$, $p<0.001)$, 전체 평균점수와 건물의 주변환경, 작업장 시설 중 조명의 항목에서 유의적으로 큰 점수 차이를 보였다.

\section{제조시설관리}

Table 4는 제조시설관리에 대한 업소 평가 점수를 제시 하고 있다. 영역의 평균은 1.00점/2.0점(50.0\%)으로 평가되 었고, $\mathrm{HACCP}$ 지정업소의 평균이 1.73 점 $(86.5 \%)$ 으로 미지 정업소 0.92 점 $(46.0 \%)$ 에 비해 유의적으로 높은 점수를 보 였다.

항목별 평가에서 가장 높게 평가된 항목은 '제조시설·설 비의 내수성 - 내부식성 재질이며 분리 세척 - 소독이 가 능한 구조'가 1.26점(63.0\%)이며 지정업소가 2.0점 $(100 \%)$, 미지정업소가 1.18 점 $(59.0 \%)$ 이었다. 다음으로 지정업소는 '칼 및 칼꽂이의 청결 및 세척·소독관리'(1.80점, $90.0 \%)$, '제조시설의 정기적 점검 및 정비기록 유지'(1.73점, $86.5 \%$ ) 의 항목이, 미지정업소는 '도마의 청결 및 세척 - 소독관 리'(1.07점, $53.5 \%)$ 와 '칼 및 칼꽃이의 청결 및 세척 - 소 독관리'(0.98점, $49.0 \%)$ 가 높은 순서로 평가되었다. 지정업
소의 경우 가장 낮게 평가된 항목으로는 '도마의 청결 및 세척·소독관리'(1.53점, $76.5 \%)$ 이었으나, 미지정업소 $(1.73$ 점, $86.5 \%$ )에 비해서는 높은 것으로 조사되었다. 미지정업 소에서 낮게 평가된 항목들은 '제조시설의 정기적 점검 및 정비기록 유지'항목과 '도마의 청결 및 세척 - 소독관리' 항목 및 '절단기 및 믹서기, 작업기기의 세척 - 소독관리 및 지침서 구비, 항목이 모두 0.67점(33.5\%)으로 나타났다. 특히 점수가 낮았던 항목 중에서 칼, 칼꽂이, 도마 등의 세척 및 소독 부분은 쇠고기 판매업소들의 위생 환경에서 작업 전 - 후 기구류의 위생적인 보관(적합률 $34 \%$ )과 세 척(적합률 67\%)실행이 저조하였다(Nam et al, 2007a)는 결 과와 서울시 전체 축산물 판매업소의 위생실태 항목 중 작업 전후의 칼, 칼갈이, 도마 등 기계·기구류에 대한 세 척(적합률 $69 \%$ ) 및 소독(적합률 $33 \%$ )이 지켜지지 않는 취 약한 부분이라는 결과(Park et al, 2007)와 크게 다르지 않 았다. 또한 실제 식중독 균의 검출이 지육의 표면과 직접 적으로 접촉되는 칼, 도마 등의 작업도구인 경우가 많으 므로 이에 대한 위생적인 처리와 관리가 요구된다(Oh et al., 2001).

제조시설관리 영역에서의 전체 평균과 모든 항목에서 $\mathrm{HACCP}$ 지정업소가 미지정업소에 비하여 평균 점수가 높 았으며 유의적인 차이를 나타내었다 $(p<0.01, p<0.001)$.

\section{보관 및 운반관리}

Table 5는 보관 및 운반관리에 대한 평가 점수를 제시 하였다. 영역의 평균은 0.93점/2.0점(46.5\%)이었고, HACCP 지정업소의 평균이 1.69 점/2.0점(84.5\%)으로 미지정업소 0.86점/2.0점(43.0\%)에 비해 유의적으로 높게 평가되었다 $(p<0.001)$.

보관 및 운반관리 영역에서 평균이 가장 높게 평가된 항목은 '입고일지의 작성 및 관리'(1.27점/2.0점, $63.5 \%)$ 였 으며, 지정업소의 경우 가장 높게 평가된 항목은 입고일 지의 작성 및 관리'(1.93점/2.0점, $96.5 \%)$, 미지정업소에서

Table 4. Comparison of facility and equipment management domain in HACCP certified and non-certified meat markets

\begin{tabular}{|c|c|c|c|c|c|}
\hline & \multirow[b]{2}{*}{ Item } & \multirow[b]{2}{*}{ Mean \pm SD } & \multicolumn{2}{|c|}{ Mean \pm SD } & \multirow[b]{2}{*}{ t-Value } \\
\hline & & & $\begin{array}{l}\text { HACCP } \\
\text { certified }\end{array}$ & $\begin{array}{c}\text { HACCP } \\
\text { not-certified }\end{array}$ & \\
\hline \multirow{6}{*}{$\begin{array}{l}\text { Facility } \\
\text { and } \\
\text { equipment } \\
\text { management }\end{array}$} & Waterproof, corrosion resistant and separate structure for cleaning & $1.26 \pm 0.67^{1)}$ & $2.00 \pm 0.00$ & $1.18 \pm 0.66$ & $14.65^{* * *}$ \\
\hline & Regular evaluation and proper maintenance of cleaning records & $0.79 \pm 0.64$ & $1.73 \pm 0.46$ & $0.70 \pm 0.57$ & $6.79 * * *$ \\
\hline & Cleanliness and sanitation of knives and knife rack & $1.06 \pm 0.74$ & $1.80 \pm 0.56$ & $0.98 \pm 0.71$ & $4.32 * * *$ \\
\hline & Cleanliness and sanitation of chopping board & $1.12 \pm 0.61$ & $1.53 \pm 0.64$ & $1.07 \pm 0.59$ & $2.85^{* *}$ \\
\hline & $\begin{array}{l}\text { Cleanliness and sanitation of cutter, blender and other machines } \\
\text { and guidebook for these }\end{array}$ & $0.76 \pm 0.67$ & $1.60 \pm 0.51$ & $0.67 \pm 0.63$ & $5.53 * * *$ \\
\hline & Total & $1.00 \pm 0.22$ & $1.73 \pm 0.18$ & $0.92 \pm 0.23$ & $7.51 * * *$ \\
\hline
\end{tabular}

\footnotetext{
1) Score: 2 (excellent), 1 (normal), or 0 (poor) out of 2 points.
} ${ }^{*} p<0.05,{ }^{* *} p<0.01,{ }^{* * *} p<0.001$. 
는 '보관 창고의 온도와 습도관리 및 기록 유지'(1.79점/ 2.0점, 89.5\%)로 나타났다. 가장 낮은 평가점수를 받은 항 목은 '냉장-냉동고의 세척·소독 관리(0.65점/2.0점, $32.5 \%$ )' 이었는데, 이 항목은 지정업소(1.1점/2.0점, 55.0\%)와 미지 정업소 $(0.60$ 점 $/ 2.0$ 점, $30.0 \%)$ 에서도 가장 점수가 낮았다. 또 미지정업소의 냉장 - 냉동고의 온도관리 항목은 0.70점 (35\%)으로 낮은 점수를 보였는데, 축산물의 판매단계에 대 한 안전관리에 있어 온도관리는 가장 중요한 항목이며, 축 산물가공처리법에서는 식육의 냉장 보관 온도 $\left(10^{\circ} \mathrm{C}\right.$ 이하 $)$ 와 냉동 보관온도 $\left(-18^{\circ} \mathrm{C}\right)$ 를 규정하고 있어, 법적 기본 요 건이므로, 이를 준수하는 것이 매우 중요하다. 운반 및 보 관시 온도 관리를 효율적으로 하기 위하여 관리부처 간 선행요건의 공통사항으로 명시해야 한다고 하였다(Hong et al., 2008). 또한 $\mathrm{HACCP}$ 이 의무적용 되는 도축과정 뿐 아니라 사육에서 도축, 보관, 운반, 판매까지 전 과정에 걸 친 예방적 안전관리를 위해서는 철저한 온도관리를 통한 cold chain유지가 필요하므로, 축산물 위생 개념이 부족한 영업자나 종업원들에 대한 관계당국 및 정부의 시급하고 적절한 교육과 홍보가 이루어져야 할 것이다(Lee, 2009; Nam et al., 2007a).

보관 및 운반관리 영역 전체 평균과 세부 항목 모두에 서 지정업소가 미지정업소에 비하여 유의적으로 높은 점 수를 보여, 식육의 보관 및 운반 단계에 대한 관리가 $\mathrm{HACCP}$ 을 통해 개선되었다는 결과를 보여주었다 $(p<0.01$, $p<0.001$ ).

\section{개인위생관리}

Table 6 은 개인위생관리에 대한 평가 점수를 제시하였 다. 영역의 평균은 0.75 점/2.0점(37.5\%)이고, $\mathrm{HACCP}$ 지정
업소의 평균이 1.51 점/2.0점(75.5\%)으로 미지정업소의 점 수 0.67 점/2.0점(33.5\%)에 비해 높은 점수를 보였으며 유 의적인 차이를 나타내었다 $(p<0.001)$.

개인위생관리 영역에서 가장 높게 평가된 항목은 ‘영업 자 및 종업원의 정기적 건강진단 실시'로 1.18점/2.0점 (59.0\%)이었으며, 지정업소가 1.93점/2.0점(96.5\%), 미지정 업소가 1.10 점 $/ 2.0$ 점 $(55.0 \%)$ 이었다. 가장 낮은 점수를 받은 항목은 '종사자의 정기적 위생 교육의 실시 및 숙지상태 평가'(0.51점/2.0점, $25.5 \%)$ 였으며, 지정업소에서도 '종사자 의 정기적 위생 교육의 실시 및 숙지상태 평가' $(1.13 / 2.0$ 점, $56.5 \%$ )이었고, 미지정업소에서는 '작업장 입구의 종사 자 손 세척 시설 구비 및 운영관리’가 0.43점/2.0점(21.5\%) 으로 가장 점수가 낮았다.

개인위생관리 영역의 모든 항목에서 $\mathrm{HACCP}$ 지정업소 가 미지정업소에 비해 유의적으로 높게 평가되었다 $(p<0.01$, $p<0.001)$. 종사자로부터의 교차오염을 방지하기 위해서는 현장에서 손세척 및 소독이 가능하고, 위생복의 분리구분, 적절한 위생복 착용(위생복, 위생모, 앞치마, 위생신발 등) 이 가능하며 청결히 보관관리 되는 것이 필요한데, $\mathrm{HACCP}$ 을 적용하는 업소의 경우 이에 대한 준비, 실행, 기록, 관 리 등이 이루어지므로 $\mathrm{HACCP}$ 을 미적용하는 업소에 비해 좋은 점수를 보여준 것으로 판단된다. 또한, $\mathrm{HACCP}$ 미적 용업소의 경우 손청결 및 위생복장 관리 이외에 장신구 착용 금지 등의 내용이 잘 지켜지지 못하는 실정이며, 이 의 효과적 실천을 위해서는 지속적인 교육과 홍보가 필요 하고, 전용 수세설비, 온수시설, 비 접촉식 수도꼭지, 비누, 손톱 솔, 종이타월, 폐달식 휴지통 등의 제반 시설이 갖추 어져야 하겠다(Lyu, 2004; Nam et al, 2007a; Nel et al, 2004; Park et al, 2007).

Table 5. Comparison of storage and transport management domain in HACCP certified and non-certified meat markets

\begin{tabular}{|c|c|c|c|c|c|}
\hline & \multirow[b]{2}{*}{ Item } & \multirow[b]{2}{*}{ Mean \pm SD } & \multicolumn{2}{|c|}{ Mean \pm SD } & \multirow[b]{2}{*}{ t-Value } \\
\hline & & & $\begin{array}{l}\text { HACCP } \\
\text { certified }\end{array}$ & $\begin{array}{c}\text { HACCP } \\
\text { not-certified }\end{array}$ & \\
\hline Receiving & Record of receiving & $1.27 \pm 0.69^{1)}$ & $1.93 \pm 0.26$ & $1.20 \pm 0.69$ & $8.310^{* * *}$ \\
\hline Returning & Proper treatment and records of returned food & $0.79 \pm 0.66$ & $1.87 \pm 0.35$ & $0.67 \pm 0.58$ & $11.57 * * *$ \\
\hline \multirow{8}{*}{$\begin{array}{c}\text { Storage } \\
\text { management }\end{array}$} & Cleanness and ventilation system in store room & $1.14 \pm 0.63$ & $1.87 \pm 0.35$ & $1.06 \pm 0.60$ & $5.08 * * *$ \\
\hline & Management and records of temperature and humidity in store room & $0.88 \pm 0.73$ & $1.80 \pm 0.56$ & $1.79 \pm 0.66$ & $5.70 * * *$ \\
\hline & Observation of first-in/first-out rule for food and materials & $0.88 \pm 0.56$ & $1.53 \pm 0.52$ & $0.81 \pm 0.52$ & $5.14 * * *$ \\
\hline & $\begin{array}{l}\text { Management of temperature: refrigerated meat }\left(-2 \sim 5^{\circ} \mathrm{C}\right) \text {, frozen } \\
\text { meat (below }-18^{\circ} \mathrm{C} \text { ) }\end{array}$ & $0.81 \pm 0.75$ & $1.87 \pm 0.35$ & $0.70 \pm 0.69$ & $10.88 * * *$ \\
\hline & No storage in the basement or near walls & $0.78 \pm 0.62$ & $1.53 \pm 0.64$ & $0.70 \pm 0.56$ & $5.41 * * *$ \\
\hline & Check packaging and expiration date of refrigerated and frozen food & $1.21 \pm 0.64$ & $1.67 \pm 0.62$ & $1.16 \pm 0.63$ & $2.96^{* *}$ \\
\hline & Cleaning and sterilization of refrigerator and freezer & $0.65 \pm 0.68$ & $1.13 \pm 0.83$ & $0.60 \pm 0.64$ & $2.95 * *$ \\
\hline & Total & $0.93 \pm 0.22$ & $1.69 \pm 0.23$ & $0.86 \pm 0.34$ & $9.16^{* * *}$ \\
\hline
\end{tabular}

${ }^{1)}$ Score: 2 (excellent), 1 (normal), or 0 (poor) out of 2 points.

${ }^{*} p<0.05,{ }^{* *} p<0.01,{ }^{* * *} p<0.001$. 
Table 6. Comparison of personal hygiene management domain in HACCP certified and non-certified meat markets

\begin{tabular}{|c|c|c|c|c|c|c|}
\hline & & \multirow[b]{2}{*}{ Item } & \multirow[b]{2}{*}{ Mean \pm SD } & \multicolumn{2}{|c|}{ Mean \pm SD } & \multirow[b]{2}{*}{$\mathrm{t}$-Value } \\
\hline & & & & $\begin{array}{l}\text { HACCP } \\
\text { certified }\end{array}$ & $\begin{array}{c}\text { HACCP } \\
\text { not-certified }\end{array}$ & \\
\hline \multirow{6}{*}{$\begin{array}{c}\text { Personal } \\
\text { hygiene } \\
\text { management }\end{array}$} & \multirow{2}{*}{ Health } & Medical examination of workers & $1.18 \pm 0.82^{1)}$ & $1.93 \pm 0.26$ & $1.10 \pm 0.81$ & $8.73^{* * *}$ \\
\hline & & Checking of health condition before work & $0.71 \pm 0.56$ & $1.33 \pm 0.72$ & $0.65 \pm 0.50$ & $3.59 * *$ \\
\hline & \multirow[b]{2}{*}{ Hygiene } & Wearing clean sanitary uniform, shoes, cap and gloves & $0.81 \pm 0.69$ & $1.60 \pm 0.63$ & $0.73 \pm 0.64$ & $4.99^{* * *}$ \\
\hline & & $\begin{array}{l}\text { Establishment of hand-wash stand in the entrance of the } \\
\text { workplace }\end{array}$ & $0.53 \pm 0.70$ & $1.53 \pm 0.64$ & $0.43 \pm 0.62$ & $6.52 * * *$ \\
\hline & \multicolumn{2}{|c|}{ Education Regular hygiene education and tests for employees } & $0.51 \pm 0.57$ & $1.13 \pm 0.35$ & $0.45 \pm 0.55$ & $6.72 * * *$ \\
\hline & \multicolumn{2}{|r|}{ Total } & $0.75 \pm 0.27$ & $1.51 \pm 0.25$ & $0.67 \pm 0.36$ & $8.72 * * *$ \\
\hline
\end{tabular}

${ }^{1)}$ Score: 2 (excellent), 1 (normal), or 0 (poor) out of 2 points.

$* p<0.05, * * p<0.01, * * * p<0.001$.

Table 7. Comparison of inspection management domain in HACCP certified and non-certified meat markets

\begin{tabular}{|c|c|c|c|c|c|}
\hline & \multirow[b]{2}{*}{ Item } & \multirow[b]{2}{*}{ Mean \pm SD } & \multicolumn{2}{|c|}{ Mean \pm SD } & \multirow[b]{2}{*}{ t-Value } \\
\hline & & & $\begin{array}{l}\text { HACCP } \\
\text { certified }\end{array}$ & $\begin{array}{c}\text { HACCP } \\
\text { not-certified }\end{array}$ & \\
\hline \multirow{4}{*}{$\begin{array}{l}\text { Inspection } \\
\text { management }\end{array}$} & $\begin{array}{l}\text { Proper inspections of facility and instruments, and regular } \\
\text { maintenance }\end{array}$ & $0.23 \pm 0.62^{1)}$ & $1.80 \pm 0.41$ & $0.06 \pm 0.34$ & $15.68 * * *$ \\
\hline & Record of inspection diary and regular education for inspectors & $0.22 \pm 0.60$ & $1.87 \pm 0.35$ & $0.04 \pm 0.26$ & $19.50 * * *$ \\
\hline & Manual for detailed inspection standardization & $0.21 \pm 0.58$ & $1.73 \pm 0.46$ & $0.04 \pm 0.26$ & $14.06^{* * *}$ \\
\hline & Total & $0.22 \pm 0.01$ & $1.80 \pm 0.35$ & $0.05 \pm 0.28$ & $18.65^{* * *}$ \\
\hline
\end{tabular}

${ }^{1)}$ Score: 2 (excellent), 1 (normal), or 0 (poor) out of 2 points.

$* p<0.05,{ }^{* *} p<0.01, * * * p<0.001$.

\section{검사관리}

Table 7은 검사관리에 대한 평가 점수를 제시하였다. 영 역의 평균은 0.22점/2.0점(11.0\%)으로 평가되었고, $\mathrm{HACCP}$ 지정업소의 평균이 1.80 점( $90.0 \%)$ 으로 미지정업소 0.50 점 (25.0\%)에 비해 높은 점수를 보였으며 유의적인 차이를 나 타내었다 $(p<0.001)$.

검사관리 영역에서 가장 높게 평가된 항목은 '제품검사 에 필요한 시설 및 기구의 구비 및 점검 - 정비기록 유무 로 0.23 점/2.0점(11.5\%)이었으며, 지정업소는 '검사기록서 의 작성과 검사종사자의 정기적 교육·훈련실시'(1.87점/ 2.0점, $93.5 \%$ )이고 미지정업소는 '제품검사에 필요한 시설 및 기구의 구비 및 점검·정비기록 유무’(0.16점/2.0점, $8.0 \%)$ 이었다.

검사관리 영역의 모든 항목별 평가에서 $\mathrm{HACCP}$ 지정업 소가 미지정업소에 비하여 유의적으로 점수가 높았다 $(p<0.001)$.

검사관리는 $\mathrm{HACCP}$ 의 지정 및 유지를 위한 필수 항목 이므로 모든 $\mathrm{HACCP}$ 지정업소가 설치되어 있는 실험실 혹은 국가에서 인정하는 축산물위생검사기관을 통해 규칙 적으로 검사를 실시하고 관련 기록 - 관리를 유지하고 있 었으나, 미지정업소의 경우 실험실을 갖춘 곳이 없었을 뿐 만 아니라 규칙적인 위탁검사를 실시하는 경우도 드물어,
두 집단의 점수 차이가 큰 것으로 여겨진다. 식육판매업 소는 규모가 작고 영세한 업종이므로, 정기적인 검사관리 가 업소에 부담이 될 수 있어, 국가에서 규칙적으로 검사 관리를 대행해 주거나, 산학 협동체제를 구축하여 인근 대 학의 시설과 인력을 활용할 수 있도록 하여 경비 절감 및 효율적인 자원 활용을 유도하는 것이 필요할 것이다(Hong et al., 2008).

\section{요 약}

본 연구는 서울 및 경기 지역 식육판매업소를 대상으로 $\mathrm{HACCP}$ 지정업소 15 곳과 $\mathrm{HACCP}$ 미지정업소 141 곳에 대 하여 평가를 위한 체크리스트와 공정한 평가를 위한 체크 리스트 기준서를 개발하여 2008년 12월 2009년 8월까지 실시하였다. 체크리스트는 업체 일반사항과 위생 관리로 구분하였으며 평가한 내용을 요약하면 다음과 같다. 첫째, 156 곳 식육판매업소의 작업장 면적은 평균 $71.05 \mathrm{~m}^{2}$ 이었 고 전체 직원은 평균 1.76 명의 정규직원과 평균 1.31 명의 비정규직 직원을 고용하였다. 거래업체 중 원료공급 업체 는 평균 1.56 개였으며, 그 중 도매업체가 평균 $60.6 \%$ 로 가 장 높은 비율을 나타내었고 다음으로 도축장이 평균 $26.4 \%$ 로 나타내어, 공급원료의 형태는 지육 보다는 대부분 정 
육인 포장육인 것으로 나타났다. 평균 2.71 개로 조사된 제 품납품업체에는 일반소비자가 평균 $75.4 \%$ 로 가장 높은 비 율을 나타냈으며, 다음으로 일반식품 접객업소가 평균 $8.7 \%$ 로 나타났다. 조사대상 업소의 지역적 분포는 서울이 $85.3 \%$, 경기도가 $14.7 \%$ 이었으며 건물 소유 형태로는 자가 건물 이 $10.3 \%$, 임대가 $89.7 \%$ 였다. 둘째, 식육판매업 위생관리 실태조사의 5 개 영역 중 가장 높은 점수를 획득한 영역은 제조시설관리 영역 $(1.00$ 점/2.0점, $50.0 \%)$ 이었고, 다음으로 보관 및 운반관리(1.93점/2.0점, $96.5 \%)$, 작업장관리(0.76점 /2.0점, $38.0 \%$ ), 개인위생관리( 0.75 점/2.0점, $37.5 \%$ ), 검사관 리(0.22점/2.0점, $11.0 \%)$ 의 순으로, 검사관리 영역이 가장 낮은 점수를 보였으며, $\mathrm{HACCP}$ 지정업소의 평균점수가 5 개 영역 모두와 전체 항목에서 미지정업소에 비하여 유의 적으로 높았다 $(p<0.05, p<0.01, p<0.001)$. 이상의 결과로 식육판매업의 $\mathrm{HACCP}$ 지정업소가 미지정업소보다 위생관 리를 잘 하고 있는 것을 알 수 있었다. 그러므로 식육판 매업의 $\mathrm{HACCP}$ 미지정업소에서는 위생관리상태의 개선이 필요하며 축산물 유통의 안전성을 위해서 좀 더 지속적인 위생지도와 관리가 필요할 것으로 여겨지고, 최종적으로 는 $\mathrm{HACCP}$ 의 적용을 통해 위생안전관리를 확보하는 것이 필요할 것으로 판단된다.

\section{감사의 글}

본 연구는 2008년 농림수산식품부 농림기술개발사업(과 제번호: 108002-02-1-CG000)의 지원에 의해 수행되었으며, 이에 감사드립니다.

\section{참고문헌}

1. FSIS (2009) Intensification of Hygiene Inspection for livestock products (news). Food Safety Information Service(in Korean).

2. Hong, C. H. and Cho, D. H. (2008) Comparative analysis of the prerequisite items applicable to the HACCP in livestock processing plants. J. Fd. Hyg. Safety. 23, 19-25.

3. Jeon. S. K., Park, J. Y., and Kim, Y. J. (2005) Study on the customers' awareness on safety of livestock Products and livestock processed foods. J. Prac. Edu. 18, 115-128.

4. KFDA (2008) Prerequisite programs for Hazard analysis critical control point of foods. Korea Food and Drug Administration, Seoul, Korea (in Korean).

5. KFDA (2009) Trends of food poisoning in Korea. Korea Food and Drug Administration. Available: http://e-stat.kfda. go.kr (in Korean).

6. Kim, O. K. (2000) Health control of livestock products. Kor. J. Vet. Publ. Health . 24, 251-261.
7. KOLPHAS (2009) Introduction of HACCP. Korea Livestock Products HACCP Accreditation Service. Available: http://www. ihaccp.or.kr/renew/user/haccp/haccp_11.asp (in Korean).

8. Lee, B. O. (2007) The structure and characteristics of HACCP system for livestock products in Korea. Kor. J. Agri. Manag. Policy. 34, 456-472.

9. Lee, H. S. (2009) 2009's safety management policy on livestock. J. Fd. Hyg. Safety. 4, 9-14.

10. Lee, J. H., Lee, B. O., and Sin, O. K. (2005) A study on evaluation of the meat safety. Kor. J. Agri. Manag.Policy. 32, 728-745.

11. Lee, J. Y. (2006) Development of the sanitation evaluation tool through researching of management practice at military foodservice. MS thesis. Yousei Univ., Seoul, Korea.

12. Lyu, K. (2004) Personal hygiene management of cooking employee for prevention of food poisoning. The Korea industry Health Association . 199, 36-39.

13. MIFAFF (2009) Statistics of Food, Agriculture, Forestry and Fisheries 2009. Ministry for Food, Agriculture, Forestry and Fisheries, Gwacheon, Korea (in Korean).

14. Nam, B. R., Nam, J. O., Park, J. M., Lee, R. M., Gu, H. J., Kim, M. H., Chang, U. J., Suh, H. J., and Kim, J. M. (2007a) Survey of the status of country-of-origin lables and hygiene on the meat markets of 4 regions in Korea. Korean J. Food Sci. Ani. Resour. 27, 122-126.

15. Nam, J. O., Nam, B. R., Park, J. M., Lee, R. M., Gu, H. J., Suh, H. J., Chang, U. J., and Kim, J. M. (2007b) Monitoring country-of-origin labels and indication contents for meat on electronic on-line trading. Korean J. Food Sci. Ani. Resour. 27, 117-121.

16. Nel, S., Lues, J. F. R., Buys, E. M., and Venter, P. (2004) The personal and general hygiene practices in the deboning room of a high through put red meat abattoir. Food Control 15, 571-578.

17. NVRQS (2006) Prerequisite programs for Livestock product HACCP. National Veterinary Research and Quarantine Service, Anyang, Korea (in Korean).

18. NVRQS (2009) Guideline for hygiene inspection of livestock product. National Veterinary Research and Quarantine Service, Anyang, Korea (in Korean).

19. Oh, Y. S. and Lee, S, H. (2001) Hygienic quality of beef and distribution of pathogens during cut-meat processing. $J$. $F d$. Hyg. Safety 16, 96-102.

20. Park, J. M., Gu, H. J., Jeong, J. Y., Chang. U. J., Suh, H. J., Kang, D. H., Kim, C. J., and Kim, J. M. (2007) Monitoring country-of-origin labels and sanitation on the meat markets in Seoul, Korea. Korean J. Food Sci. Ani. Resour. 27, 122126.

21. USDA (1990) HACCP 9-generic HACCP model for meat and poultry products with secondary inhibitors, not shelf stable. http://www.fsis.usda.gov

(Received February 23, 2010/Accepted April 16, 2010) 